\title{
O processamento cognitivo na leitura de uma prova de redação do Enem
}

\author{
Cognitive processing in the reading of an Enem \\ essay test
}

\begin{abstract}
Alcione Tereza Corbari*
RESUMO: Este artigo tem como objetivo refletir, com base na perspectiva sociocognitivainteracionista, sobre o processamento cognitivo da leitura de uma proposta de redação do Enem considerando os conhecimentos demandados em tal situação de interação. A partir de uma pesquisa qualitativa, propõe-se uma análise descritivo-interpretativa sob o viés do paradigma interpretativista, sustentada em revisão bibliográfica e motivada por experiências da professorapesquisadora. Os resultados apontam que a leitura da proposta de redação envolve uma atividade sociocognitivamente complexa, que movimenta a ativação dinâmica de conhecimentos diversos (linguísticos, enciclopédico, situacional, sociocultural e interacional) imprescindíveis para a compreensão do texto.
\end{abstract}

PALAVRAS-CHAVE: leitura; cognição; Enem.

ABSTRACT: This article aims to reflect, from a socio-cognitive-interactionist perspective, on the cognitive processing involved in the reading of an Enem essay proposal considering the knowledge demanded in this interactional situation. According to a qualitative research, we propose a descriptive-interpretative analysis under the interpretative paradigm. The analysis, motivated by the experiences of the teacher-researcher, is supported by bibliographic review. The results point out that the reading of the writing proposal involves a complex sociocognitive activity, which comprises a dynamic activation of different kinds of knowledge (linguistic, encyclopedic, situational, sociocultural and interactional) that are essential for the comprehension of the text.

KEYWORDS: reading; cognition; Enem.

*Doutora, Professora Adjunta dos cursos de Graduação e de Pós-Graduação em Letras da Unioeste, campus de Cascavel. E-mail: alcione corbari@hotmail.com, ORCID 0OOO-0002-32477191. 


\section{Introdução}

Falar em produção de texto na escola implica falar de leitura e interpretação. Referimo-nos tanto à leitura de modo mais amplo, aquela necessária à formação de conceitos e opiniões sobre fatos e fenômenos tematizados na produção do texto, quanto à leitura mais pontual de textos ou fragmentos de textos que vão orientar a produção escrita. Segundo um modelo cognitivo de compreensão e produção de texto, já nesse momento da leitura, que antecede a produção propriamente dita, precisamos acionar informações provindas de vários níveis, que interagem de forma complexa (VAN DIJK, 2016a).

Partindo desse pressuposto, neste artigo, apresentamos reflexões sobre a complexidade que envolve o exercício de produção do texto ainda antes da escrita da primeira palavra. Nosso olhar se volta aos conhecimentos demandados para a leitura da prova de redação do Exame Nacional do Ensino Médio (Enem) de 2008. A análise descritivo-interpretativa está pautada na perspectiva da pesquisa qualitativa e segue a premissa do paradigma interpretativista de que o pesquisador é parte do mundo que ele pesquisa e lança ao corpus um olhar balizado por seus interesses e por suas experiências relativas ao fenômeno estudado (BORTONI-RICARDO, 2008).

Portanto, a interpretação é aqui compreendida como a busca de perspectivas seguras em acontecimentos particulares e por insights particulares (MOREIRA; CALEFFE, 2008), mas assentadas em teorias e parâmetros postos e aceitos na área da Linguística Textual, especificamente aqueles propostos por estudos sociocognitivo-interacionistas, que tomam a cognição como um fenômeno situado. Assim, descrevemos e interpretamos o corpus em uma tentativa de compartilhar significados com outros (MOREIRA; CALEFFE, 2008), visando a contribuir para reflexões linguísticas, especialmente no âmbito do ensino de língua portuguesa.

A pretensão não é explorar o tema de forma exaustiva, pois nem todos os aspectos envolvidos em estratégias de ativação de conhecimentos serão abordados ou suficientemente explorados. A intenção é promover reflexão sobre 
a complexidade envolvida na atividade de leitura e, de forma indireta, na atividade de produção textual, uma vez que, no contexto de interação investigado, o êxito da produção escrita depende do êxito da leitura da proposta de redação.

Para responder ao objetivo acima apresentado, organizamos este metatexto da seguinte forma: de início, fazemos uma breve contextualização do contexto escolar que movimentou este estudo, pontuando a pergunta de pesquisa que nos propomos a responder. Nas seções seguintes, passamos a discutir os diferentes tipos de conhecimentos acionados. Partimos de uma visão holística, considerando a leitura global da proposta, em direção a um olhar mais específico, levando em conta os tipos de conhecimentos que precisam ser acionados no processamento do texto. Por fim, apresentamos as considerações finais.

\section{Inquietações sobre a leitura da proposta: contextualizando a gênese da pesquisa}

Em 2010, eu ${ }^{1}$ era professora do Ensino Médio e estava no início do processo de doutoramento. Para a composição do corpus de minha pesquisa, propus a duas turmas de $3^{\circ}$ ano de uma escola pública atividades voltadas à produção de texto que abarcassem conteúdos previstos para o terceiro ano e, ao mesmo tempo, pudessem responder a meu interesse de investigação. Embora minha tese não trate especificamente do processo de produção textual ${ }^{2}$, o procedimento instaurado me levou a refinar algumas reflexões sobre esse eixo que já acompanhavam minha prática docente nos ensinos Fundamental e Médio. Para a formação do corpus da tese, parti da proposta de redação do Enem/2008. A proposta pauta a influência do desmatamento no ciclo hidrológico, focalizando a importância das chuvas originadas na floresta amazônica em termos ecológicos, econômicos e sociais. A prova solicita ao candidato a defesa de uma entre três

\footnotetext{
${ }^{1}$ Nessa seção, optamos por usar a primeira pessoa do singular, haja vista nossa inserção no contexto da pesquisa.

${ }^{2}$ A tese trata da modalização linguística.
} 
possíveis ações que lhe são apresentadas para preservar a "máquina de chuva" da Amazônia, considerando possibilidades e limitações dessa ação.

Conforme observo em Corbari (2013), no trabalho proposto, primeiramente foram abordadas características sociointeracionais e linguísticas do artigo de opinião3. Apenas após essa abordagem inicial do gênero é que foi apresentada aos estudantes a proposta de redação ${ }^{4}$. Do primeiro contato com o texto surgiu uma tensão generalizada, situação em que grande parcela dos estudantes expressou dificuldade em realizar a leitura da proposta e, consequentemente, em produzir o texto. Minha experiência no ensino básico me permitiu concluir que a complexidade da proposta poderia ser, em grande medida, um fator que dificultava uma interação condizente com o esperado naquele movimento interlocutivo.

Embora essa primeira apresentação da proposta tivesse como objetivo apenas estabelecer um primeiro contato dos estudantes com a prova do Enem, inclusive para que estivessem cientes das dificuldades que poderiam lhes acercar na situação de exame a que estavam prestes a se submeter, a tensão que se estabeleceu, em ambas as turmas, despertou-me um olhar mais aguçado para a proposta. Busquei, então, descentrar-me de minha condição de professora, leitora madura, e projetar-me a partir da perspectiva dos estudantes, para tentar entender o motivo de a proposta parecer ilegível para grande parte deles.

A prova indica que, na produção do texto, o estudante precisa "utilizar os conhecimentos adquiridos e as reflexões feitas ao longo de sua formação" (BRASIL, 2008, p. 1). Interessei-me em observar tais estratégias de ativação de conhecimentos no momento anterior à produção propriamente dita, o que me levou à seguinte pergunta de pesquisa: Afinal, que conhecimentos são demandados na leitura dessa proposta de produção textual?

Nessa mesma época em que ocorreu esse trabalho específico, eu começava minha atuação como docente do Ensino Superior, no curso de Letras. Uma das

\footnotetext{
3 Escolhemos esse gênero por ser o que mais se aproxima da proposta dada na prova do Enem, a qual focaliza a estrutura do texto dissertativo-argumentativo.

4 Após esse contato inicial, foram propostas diversas atividades visando à exploração da temática, bem como ao trabalho com o gênero (CORBARI, 2013).
} 
disciplinas que ministrava à época tratava de questões do texto, sendo tópico de ensino os tipos de conhecimentos ativados em interações sustentadas por textos orais e escritos. Essa experiência motivou a abordagem dessa mesma proposta de redação com o intuito de promover uma ponte entre a perspectiva sociocognitiva da leitura e contextos reais de ensino de língua portuguesa.

Assim, surgiu a necessidade de uma pesquisa sistemática, que, anos mais tarde, voltei a revisitar. Achei, então, pertinente a publicação de seus resultados, uma vez que este estudo pode contribuir para a formação inicial ou continuada de professores de língua portuguesa, por propor-se a aplicar a teoria apresentada nos cursos de Letras em um contexto de leitura advindo de uma situação bastante recorrente na esfera escolar.

Figura 1 - Proposta de produção textual Enem/2008 


\section{PROPOSTA DE REDAÇÃO}

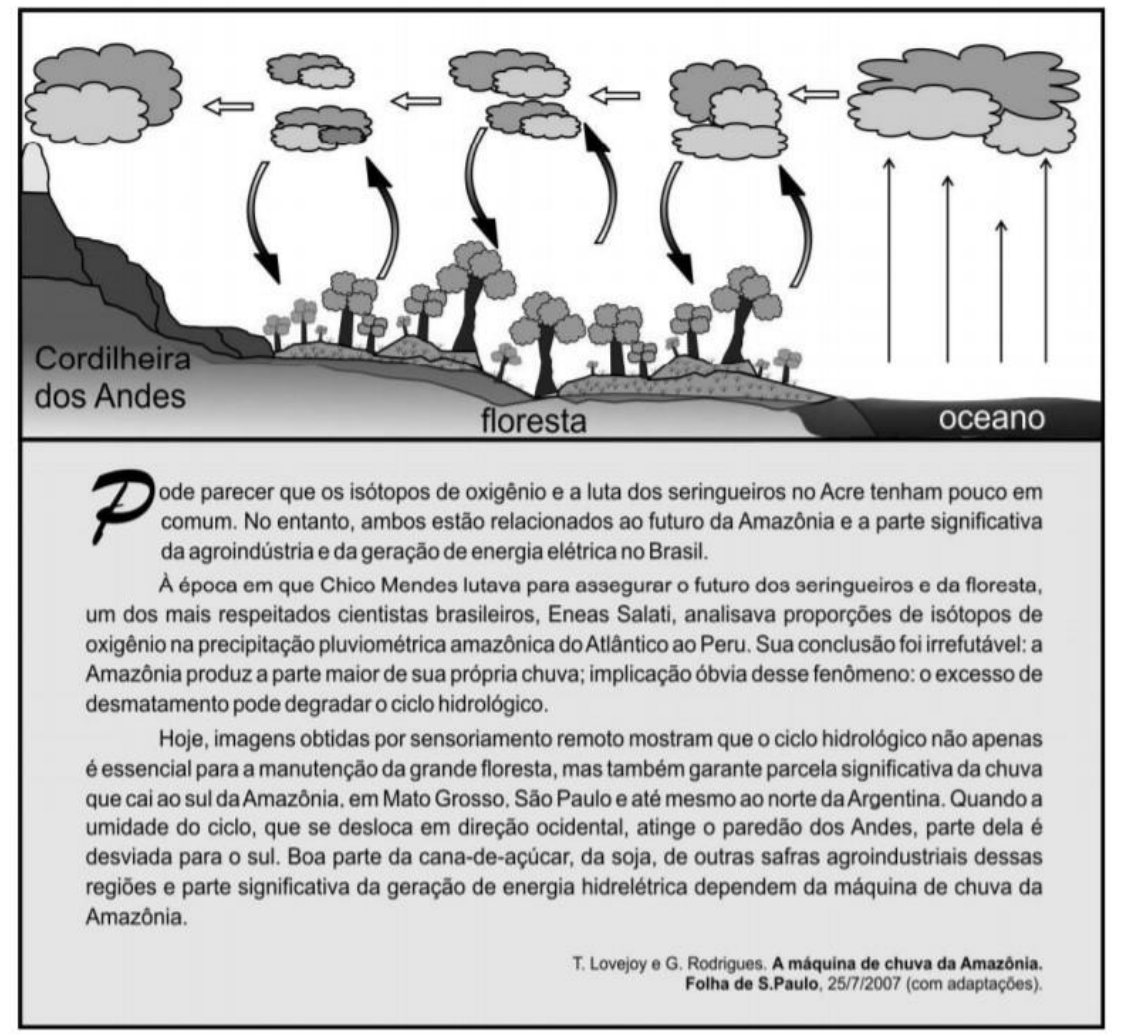

O texto acima, que focaliza a relevância da região amazônica para o meio ambiente e para a economia brasileira, menciona a "máquina de chuva da Amazônia". Suponha que, para manter essa "máquina de chuva" funcionando, tenham sido sugeridas as açōes a seguir:

1 suspender completa e imediatamente o desmatamento na Amazônia, que permaneceria proibido até que fossem identificadas áreas onde se poderia explorar, de maneira sustentável, madeira de florestas nativas;

2 efetuar pagamentos a proprietários de terras para que deixem de desmatar a floresta, utilizando-se recursos financeiros internacionais;

3 aumentar a fiscalização e aplicar pesadas multas àqueles que promoverem desmatamentos não-autorizados.

Escolha uma dessas açōes e, a seguir, redija um texto dissertativo, ressaltando as possibilidades e as limitações da ação escolhida.

Ao desenvolver seu texto, procure utilizar os conhecimentos adquiridos e as reflexōes feitas ao longo de sua formação. Selecione, organize e relacione argumentos, fatos e opiniões para defender seu ponto de vista, sem ferir os direitos humanos.

Observaçōes:

- Seu texto deve ser escrito na modalidade padrăo da lingua portuguesa.

- O texto não deve ser escrito em forma de poema (versos) ou narração.

- O texto com até 7 (sete) linhas escritas será considerado texto em branco.

- O rascunho pode ser feito na última página deste Caderno.

- A redação deve ser passada a limpo na folha própria e escrita a tinta.

ENEM 2008 PROVA1-AMARELA-PÁGINA 1 ENEM 2008

Fonte: BRASIL, 2008, p. 1.

Vale aqui observar que, no desenvolvimento da análise, descentralizamonos da experiência vivenciada em sala de aula para pensar nessa experiência ambientada na aplicação da prova do Enem. É o que fazemos, por exemplo, quando refletimos sobre os frames ativados para a compreensão da proposta de redação em 
referência ao contexto de aplicação da prova do Enem. Ainda assim, resguardadas as especificidades de cada situação, de forma geral, as reflexões aqui apresentadas são extensivas ao contexto de produção que se dá em sala de aula.

Após essa contextualização da pesquisa, na próxima seção, iniciamos o percurso teórico, ao mesmo tempo em que vislumbramos sua aplicação no contexto especificado, partindo de uma compreensão global da interação.

\section{Desvendando a prova: a compreensão global da interação}

Van Dijk (2016a) propõe um modelo de processamento do discurso baseado no pressuposto de que se trata de "um processo estratégico no qual uma representação mental na memória é construída a partir do discurso, usando informações externas e internas, com o objetivo de interpretar (entender) o discurso" (VAN DIJK, 2016a, p. 16).

Segundo Van Dijk e Kintsch (1983), na produção, compreensão e reprodução do discurso, recorremos a estratégias sociocognitivas. Trata-se de estratégias procedurais, que se constituem como uma instrução global para cada escolha a ser feita no curso da ação e implicam o uso de vários tipos de conhecimento que armazenamos na memória. Van Dijk (2016a) observa que tais estratégias são objeto aberto e fazem parte de nosso conhecimento geral; são como hipóteses operacionais eficazes sobre a estrutura e o significado corretos de um fragmento de texto.

Algumas dessas estratégias podem ser chamadas de linguísticas, especialmente aquelas que fazem um link entre o que está posto na superfície textual e as representações semânticas subjacentes; mas outras envolvem questões cognitivas mais gerais, como conhecimento de mundo, conhecimento episódico, opiniões, crenças, atitudes, interesses, planos e objetivos.

No que tange à estrutura semântica do discurso, as estratégias são construídas com base em três níveis de representação: microestrutural, macroestrutural e superestrutural (VAN DIJK; KINTSCH, 1983; VAN DIJK, 1977, 
2016a). A microestrutura diz respeito a um nível mais local do discurso, responsável pela organização sequencial e pela coerência local do discurso. Esse nível de análise está relacionando, por exemplo, à possibilidade de o leitor estabelecer relações entre duas orações. Tomemos como exemplo este período da prova: "Selecione, organize e relacione argumentos, fatos e opiniões para defender seu ponto de vista, sem ferir os direitos humanos" (BRASIL, 2008, p. 1).

Nesse caso, um conhecimento do nível microestrutural permite ao leitor perceber que as três primeiras orações estão em paralelo, tendo em comum o mesmo complemento (composto por três núcleos); que tais orações apresentam conteúdos dados como meio para se alcançar aquilo que é expresso na oração final; que a oração modal que encerra o período atua sobre a oração final etc.

A compreensão da microestrutura é fundamental para se chegar à compreensão da macroestrutura 5 , a qual se relaciona ao conteúdo global do discurso. É a partir da recuperação da macroestrutura que o leitor conseguirá compreender as ideias-chave do texto como um todo, envolvendo a noção de tema ou tópico do discurso (VAN DIJK, 1977). Por exemplo, o texto-base dado na proposta de redação como suporte para o debate está conceitualmente organizado por macroproposicões, tais como "O desmatamento pode degradar o ciclo hidrológico" e "Amazônia é essencial para a manutenção do ciclo hidrológico de grande parte da América do Sul”.

A superestrutura, por sua vez, determina formas específicas de certos tipos de discurso (narração, exposição, argumentação etc.). A proposta de redação em análise é predominantemente injuntiva, pois relaciona recursos linguísticos voltados à instrução do interlocutor acerca de um determinado procedimento. No entanto, ela mobiliza também um texto-base, que se apresenta com características predominantes de tipo expositivo. Faz parte desse texto-base, ainda, um texto multissemiótico, que participa da coerência global da proposta.

5 Conforme Van Dijk e Kintsch (1983), a macroestrutura permite unificar o texto num tópico, por meio de operações chamadas de macrorregras (de generalização, de supressão, de integração e de construção) que atuam no nível microestrutural, gerando um nível de representação global envolvendo conceitos e fatos tratados no texto. 
Nesse sentido, o gênero em tela apresenta uma superestrutura complexa, complexidade esta que pode ser facilmente reconhecida como um texto coerente pelo leitor quando este aciona episódios sociais de interação relacionados à escola, de forma geral, e à produção de texto, de forma específica.

Avaliando nosso corpus com relação à estrutura semântica do discurso, a partir dessa perspectiva teórica, ao ler a proposta de redação, o estudante 6 constrói na memória episódica uma representação textual, definida em termos de conceitos e proposições. Nessa dinâmica, paralelamente à representação semântica do discurso, constrói-se um modelo episódico ou de situação, recorrendo-se, para isso, à memória de situações similares, isto é, à "representação cognitiva dos acontecimentos, ações, pessoas, e, de forma geral, a situação sobre a qual o texto se baseia" (VAN DIJK, 2016a, p. 24).

No caso em tela, a interpretação adequada do texto está relacionada a experiências prévias dos estudantes envolvendo tanto bases textuais recuperadas de situações escolares semelhantes quanto instanciações de conhecimento mais geral da memória semântica sobre tais situações (conhecimento episódico). Nesse sentido, a leitura do texto envolve uma dinâmica de representações que é alimentada por informações que ultrapassam o nível linguístico, como o tipo de situação interativa e os objetivos gerais dos interlocutores.

Se o estudante tiver dificuldade de ativar e atualizar o conhecimento episódico e o conhecimento semântico mais geral, tal situação levará à dificuldade de alinhamento de estratégias em direção à produção de informações (representações semânticas, pragmáticas, interacionais e contextuais) compatíveis com os objetivos gerais que movimentam a interação. A ativação do conhecimento estratégico depende, pois, entre outras coisas, da quantidade de conhecimento disponível a partir do texto e do contexto, do nível de processamento ou do grau de coerência exigidos para a compreensão (VAN DIJK, 2016a).

\footnotetext{
${ }^{6}$ Para facilitar a referência, optamos por denominar de 'estudante' o leitor da prova, a pessoa que presta o exame do Enem.
} 
Segundo Van Dijk (2016a), essa gama de fatores que entram em ação no processamento estratégico resulta em uma reconstrução subjetiva, pois o leitor tenta reconstruir não apenas o significado intencionado do texto - sinalizado por pistas textuais e contextuais -, como também um significado que diga respeito a seus interesses e objetivos. Em outros termos, para interpretar adequadamente o ato de fala envolvido na proposta de redação, é imprescindível que o leitor relacione certos propósitos, certas intenções e certas ações linguísticas a estados e eventos contextuais. Tal interpretação é condição fundamental para que a ação esperada (produção de texto) se realize de forma exitosa.

Ao participar da prova do Enem, o estudante interpreta a situação de interação recorrendo à memória episódica, ativando frames que remontam a outras experiências escolares e a práticas relativas a exames e produção textual. Nesse processo, precisa relacionar as informações relativas ao contexto comunicativo de que participa (exame) e aquelas dadas na proposta de redação com o conhecimento linguístico mais geral e outros conhecimentos arquivados na memória para chegar a uma interpretação adequada tanto do ato de fala desenhado nessa proposta - considerando as intenções e os objetivos pragmáticos que guiam sua produção - quanto do referente, do conteúdo apresentado, para, por fim, chegar à execução da atividade que lhe é exigida.

Ao entrar em contato com uma proposta de redação, o estudante deve compreendê-la dentro de um processo de comunicação, no qual recebe informações de um falante (no caso, uma instituição: Instituto Nacional de Estudos e Pesquisas Educacionais Anísio Teixeira - Inep), reconhece a si mesmo como parte dessa interação e o papel dos interactantes. Essa contextualização é fundamental para que compreenda o ato de fala que lhe é dirigido e responda com o ato de fala que lhe é solicitado, o que mostra que estamos lidando não só com objetos linguísticos, mas também com resultados que advêm de algum tipo de ação social (VAN DIJK, 2016a), conforme exploramos na próxima seção. 


\subsection{Ativação de frames: a recuperação de episódios sociais de interação}

Van Dijk (2016a) observa que a verdadeira compreensão dos enunciados como realizando determinados atos de fala está amparada em um complexo processo que envolve o uso de vários tipos de informações e um conhecimento geral, que não é amorfo, mas organizado em sistemas conceituais. $\mathrm{O}$ autor afirma que uma das formas de explicar tal organização seria recorrendo ao conceito de frames (ou scripts): "Frames não são 'porções' arbitrárias do conhecimento. Antes de tudo eles são unidades de conhecimento, organizadas segundo um certo conceito [...] [que] contêm as informações essenciais, típicas e possíveis, associadas a tal conceito" (VAN DIJK, 2016a, p. 78).

$\mathrm{O}$ autor salienta a natureza mais ou menos convencional dos frames, e, analisando a relação entre estes e ato de fala, observa a importância da análise do contexto social, começando pelo contexto social mais geral, que envolve as seguintes categorias: i. privado; ii. público; iii. institucional/formal; e iv. informal. Tendo passado por essa caracterização global, os diferentes contextos sociais são definidos pelas seguintes categorias: i. posições; ii. propriedade; iii. relaçõe; e iv. funções.

Conforme Van Dijk (2016a), o pressuposto da funcionalidade (social) tem como primeira implicação cognitiva o fato de os usuários da língua construírem uma representação não só do texto, mas também do contexto social. Tendo em mente que a proposta de redação realiza um ato de fala, entendemos que o primeiro ponto para se chegar ao cumprimento do que é demandado é justamente que o estudante entenda esse ato de fala como tal e consiga se localizar naquela interação, reconhecendo seu papel social e os papéis dos outros (fiscal, corretor, Inep etc.).

Para tanto, de acordo com Van Dijk (2016a), é preciso acionar diferentes tipos de informação, organizadas em frames. No caso específico analisado, é necessário recuperar certos episódios de interação social relativos a episódios de testes. Porém, a compreensão de acontecimentos e eventos discursivos requer 


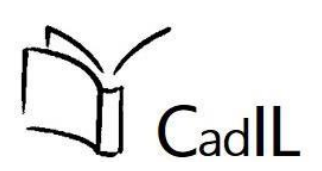

antes a construção de um conhecimento mais geral a respeito de tais acontecimentos, o que vai alçá-lo para o contexto escolar.

Usando o esquema de Van Dijk (2016a, p. 86-87) e considerando o contexto de exame do Enem, teríamos, então, as seguintes características:

Tipo de contexto social: institucional público

Instituição: MEC/Inep

Frame: realização de teste A.

Estrutura do frame:

a) Cenário: sala de aula (possivelmente de alguma instituição que não frequentou anteriormente)

b) Funções: $\mathrm{F}(\mathrm{x})$ instituição que elaborou a prova e que fará sua correção (Inep); G(y) estudantes

c) Propriedades: $x$ tem uma função constituída de produzir teste que avalia os conhecimentos ao final do Ensino Médio (Enem) e de avaliar a prova objetiva e a prova de redação conforme os critérios estabelecidos; y é um indivíduo que cumpre com as prerrogativas para realizar o teste (estudante - provavelmente - concluinte do Ensino Médio ou egresso desse nível de ensino, que foi devidamente inscrito para o teste)

d) Relações: $F(x)$ tem autoridade sobre $G(y)$

e) Posições: $y$ é avaliado por x; $x$ avalia y

B. Convenções do Frame (regras, normas etc.):

a) Cada inscrito deve receber uma prova elaborada pelo Inep

b) Cada inscrito deve responder individualmente a prova, inclusive a prova de redação

c) O inscrito que não realizar a prova de redação será desclassificado

d) O inscrito deve realizar a prova de redação conforme as orientações que constam na folha da proposta

e) O inscrito poderá fazer um rascunho da prova antes de transcrever para a folha da versão definitiva 
f) O Inep tem poder para fazer correção da prova

g) Etc.

Ações antecedentes: o candidato se inscreveu para a realização da prova de redação; preparou-se com os instrumentos solicitados (documento e caneta); adentrou ao local de prova no horário estabelecido; aguardou o início da prova; folheou a prova; acessou a prova de redação etc.

Nesse tipo de contexto, é bem provável que um enunciado como aquele apresentado na Figura 1 (prova de redação) seja tomado como uma proposta cuja aceitação é obrigatória caso o candidato queira obter êxito na interação social em questão.

Com base na análise de Van Dijk (2016a), apenas os candidatos que têm conhecimento das informações contextuais dadas acima, entre outras, serão capazes de julgar a validade do ato de fala. Se um dos traços contextuais não estiver presente, a injunção/instrução poderá perder força ou até ser anulada como ato de fala. Pensemos no caso da aplicação da proposta em sala de aula, conforme relato apresentado no início deste texto: embora a proposta de redação continue sendo exatamente a mesma aplicada no exame do Enem/2008, o contexto social imediato reconfigura o ato de fala.

Então, para que ocorra a compreensão pragmática, segundo Van Dijk (2016a), o usuário da língua deve levar em consideração as seguintes informações sobre o contexto geral: seu tipo específico, o frame do contexto posto em relevância, as propriedades/relações das posições sociais, as funções e os membros envolvidos. Ou seja, a análise de um contexto particular é apoiada pelo conhecimento geral da estrutura social.

Tal compreensão, no entanto, embora imprescindível, não é suficiente para o processamento do texto. Outros conhecimentos e outras estratégias precisam ser ativados, conforme abordamos na próxima seção. 


\section{Sistemas de conhecimento requeridos no processamento da prova de redação}

Van Dijk (2016b) observa que, além de outras estruturas de modelos mentais semânticos e pragmáticos subjacentes à compreensão do discurso, o conhecimento mútuo e compartilhado, bem como seu domínio e expressão constante, constituem aspecto fundamental da interface cognitiva do discurso e do ambiente social. Sem tal componente epistêmico cognitivamente (e socialmente) baseado, vários aspectos da leitura não podem ser explicados.

Estamos nos referindo tanto a conhecimentos relativos à situação social de interação quanto a outros tipos de conhecimento. Sem recuperar os conhecimentos que o produtor do texto pressupõe serem compartilhados com o leitor/ouvinte, a compreensão será deficitária. Para debater essa questão, além da orientação teórica já citada (VAN DIJK; KINTSCH, 1983; VAN DIJK, 1977, 2016a, 2016b), recorremos aos estudos de Kleiman (2016), Koch (2003) e Koch e Elias (2006, 2010), que fazem uma abordagem didática dos tipos de conhecimentos requeridos nas interações estabelecidas/mediadas pelo texto.

Koch (2003) explica que três grandes sistemas de conhecimentos concorrem para o processamento textual: o linguístico, o enciclopédico/de mundo, o interacional/sociointeracional7. Segundo Koch e Elias (2006, 2010), tais conhecimentos, que resultam de inúmeras atividades em que nos envolvemos ao longo de nossas vidas, deixam entrever a intrínseca relação entre linguagem/mundo/práticas sociais.

Kleiman (2016) observa que essa combinação de diferentes níveis de conhecimento que interagem entre si caracteriza a leitura como um processo interativo. Essa dinâmica aponta para o papel ativo do leitor, pois este mobiliza um conjunto complexo de informações armazenadas na memória, a partir de experiências anteriores, para a compreensão do texto. Conforme Koch (2003), o

\footnotetext{
7 A autora afirma que tais categorias estão pautadas na teoria apresentada por Heinemann e
} Viehweger (1991). 
leitor vai realizar vários passos interpretativos de maneira simultânea e rápida, ativando estratégias cognitivas, que consistem em algum cálculo mental, como ocorre com as inferências, processo em que nova informação semântica é criada com base em informações dadas em determinado contexto ( $\mathrm{KOCH}, 2003)$.

Isso quer dizer que, ao entrar em contato com um texto, considerando o conteúdo linguístico e o contexto social de interação, o estudante faz uma ponte entre aquilo que lê e os conhecimentos de que já dispõe, ampliando-os ou transformando-os: "constrói novas representações mentais e/ou estabelece uma ponte entre segmentos textuais, ou entre informação explícita e informação não explicitada no texto" (KOCH, 2003, p. 50). Na sequência, abordamos esses conhecimentos em subseções específicas e estabelecemos a relação com o corpus analisado.

\subsection{Conhecimento Linguístico}

O conhecimento linguístico pressupõe a decodificação estrutural de fonemas/letras e a construção de morfemas e, num nível linguístico mais amplo, diz respeito a conhecimentos de ordem gramatical e lexical e referente à ortografia da língua (KOCH, 2003; KOCH; ELIAS, 2006, 2010). Koch e Elias (2006) observam que, com base nesse tipo de conhecimento, podemos compreender: a organização do material linguístico, o uso dos meios coesivos para efetuar a remissão ou sequenciação textual e a seleção lexical adequada ao tema ou aos modelos cognitivos ativados.

Kleiman (2016) afirma que o conhecimento linguístico é conhecimento implícito, não verbalizado e não verbalizável na maioria das vezes, responsável por fazer com que falemos português, abrangendo desde conhecimento sobre a pronúncia de palavras no português, sobre o vocabulário e as regras da língua e sobre o uso da língua.

A partir da perspectiva de Van Dijk (1977, 2016a, 2016b) e Van Dijk e Kintsch (1983), considerando a estrutura semântica do discurso, podemos 
interpretar que esse conhecimento está circunscrito ao nível de representação microestrutural, o qual é imprescindível para se chegar a uma representação macroestrutural. Tomando em conta a proposta de redação, observamos que, para compreendê-la, o leitor deve ativar conhecimentos linguísticos referentes à língua portuguesa na modalidade escrita. Tomemos como exemplo inicial o primeiro parágrafo do texto base:

Pode parecer que os isótopos de oxigênio e a luta dos seringueiros no Acre tenham pouco em comum. No entanto, ambos estão relacionados ao futuro da Amazônia e a parte significativa da agroindústria e da geração de energia elétrica no Brasil (BRASIL, 2008, p. 1, destaque meu).

No âmbito sintático, é necessário identificar cada constituinte e interpretar sua função na sentença, como, por exemplo, as relações de regência: os constituintes "o futuro da Amazônia e parte significativa da angroindústria e da geração elétrica no Brasil" estão subordinados ao adjetivo "relacionados"; os sintagmas nominais “a agroindústria” e "a geração elétrica no Brasil”, por sua vez, estão sob a regência do substantivo "parte".

A esse processamento sintático (KLEIMAN, 2016) agrega-se o processamento lexical (KLEIMAN, 2016). Assim, elementos como os sintagmas "isótopos de oxigênio", "precipitação pluviométrica”, “ciclo hidrológico" e "sensoriamento remoto" precisam ser compreendidos não apenas como termos que preenchem determinadas função sintáticas, mas também como itens lexicais reconhecíveis e adequados ao tema ou aos modelos cognitivos ativados.

Além disso, no estabelecimento da coerência local, conforme observa Van Dijk (1977), as sentenças em uma sequência de discurso são interpretadas em relação à interpretação de outras sentenças, estabelecendo uma coerência linear. Por exemplo, na primeira frase, há uma relação entre “isótopos de oxigênio" e "a luta dos seringueiros", linguisticamente marcada pelo operador “e”, relação esta imprescindível para a compreensão do texto.

No movimento de interpretação do texto, requer-se, ainda, a inferência de que aquilo que é dado como conteúdo proposicional no primeiro período, em que ocorre verbo modal + verbo parecer e o uso do modo subjuntivo, será reavaliado 
no segundo. Em termos ducrotianos (DUCROT, 1987), diríamos que essas características linguísticas já encaminham o leitor para a interpretação de que ocorrerá uma reorientação da argumentação no encadeamento, o que é confirmado pelo uso do operador argumentativo "No entanto", que inicia o segundo período, encaminhando o leitor para a relação adversativa entre o conteúdo do primeiro e do segundo período.

Ainda citamos a relação coesiva estabelecida pela referência a "ambos". A retomada viabilizada por esse elemento coesivo precisa ser reconhecida para que se confira sentido ao texto. Também o termo "pouco", em "Pode parecer que os isótopos de oxigênio e a luta dos seringueiros no Acre tenham pouco em comum”, precisa ser reconhecido como um elemento que, numa escala argumentativa, aponta para a negação, diferente do sentido atualizado pelo operador argumentativo "um pouco" (DUCROT, 1989).

Tomando outros exemplos do texto-base, para além do primeiro parágrafo, observamos que outros conhecimentos linguísticos são requeridos do leitor, tais como aqueles relacionados à habilidade de reconhecer/recuperar:

Algumas cadeias semânticas, como as palavras/expressões relativas aos campos hidrológico (isótopos de oxigênio, energia elétrica, precipitação pluviométrica, chuva, ciclo hidrológico, máquina de chuva, umidade), florestal (floresta, seringueiros, Amazônia, amazônica, desmatamento), agroindustrial (agroindústria, cana-de-açúcar, soja, safras agroindustriais) e científico (cientista, analisava, conclusão), entre outros.

- Informações semânticas relativas ao léxico atualizado: por exemplo, reconhecer determinados substantivos (Acre, Brasil Atlântico, Peru, Amazônia, Mato Grosso, São Paulo, Argentina e Andes) como topônimos, e "Chico Mendes" e "Eneas Salati" como nomes próprios, o que justifica o uso de iniciais maiúsculas, conforme a ortografia da língua portuguesa.

Relações de coesão referencial: por exemplo, recuperar os referentes de "esse fenômeno", no último fragmento citado no parágrafo anterior, bem como os referentes dos elementos em destaque nestes fragmentos: "Boa parte da canade-açúcar, da soja, de outras safras agroindustriais dessas regiões”, 
"parte dela é desviada para o sul”, “sua conclusão foi irrefutável”, "mostram que o ciclo hidrológico não apenas é essencial para a manutenção da grande floresta”, além de outros termos e do recurso à repetição lexical.

Relações anafóricas mais complexas, como as que permitem dar sentido aos sintagmas "ciclo hidrológico", que aparece ao final do primeiro parágrafo, e "a máquina de chuva da Amazônia”, que aparece ao final do textobase.

A função sintático-semântica dos apostos destacados nestes fragmentos: "um dos mais respeitados cientistas brasileiros, Eneas Salati"; e "implicação óbvia desse fenômeno: o excesso de desmatamento pode degradar o ciclo hidrológico".

- $\quad$ Relações dadas por escalas argumentativas (DUCROT, 1987), como ocorre na atualização do operador argumentativo "até mesmo", em “[...] mas também garante parcela significativa da chuva que cai ao sul da Amazônia, em Mato Grosso, São Paulo e até mesmo ao norte da Argentina”.

Elementos dêiticos que localizam a interação no tempo e no espaço, como aquele estabelecido pelo advérbio destacado neste fragmento: "Hoje, imagens obtidas por sensoriamento remoto mostram que o ciclo hidrológico não apenas é essencial para a manutenção da grande floresta [...]”.

- $\quad$ A função textual-discursiva da pontuação, que serve à coesão e à organização textual e também orienta sentidos.

- $\quad$ Pressupostos acionados a partir do conteúdo posto no texto.

- $\quad$ Etc.

Ainda outros aspectos linguísticos poderiam ser apontados. Apresentamos apenas alguns exemplos (e considerando apenas parte da proposta: o texto-base) que ilustram a importância do conhecimento linguístico para o processamento do texto e explicitam a complexidade envolvida em uma proposta de produção textual. Mesmo quando olhamos apenas o aspecto linguístico, focando a coerência local, a microestrutura do texto, explicita-se a complexidade envolvida no ato de leitura, que demanda a ativação de muitos conhecimentos de diferentes níveis linguísticos. 
Tomando em conta o campo lexical - que se enfatizou como um fator de dificuldade de leitura entre os estudantes -, podemos dizer que, se o leitor não puder acessar conhecimentos suficientes para interpretar o sentido de alguma palavra ou expressão, é possível recuperar o sentido pelo contexto, pois este pode atuar como suporte para o processo de inferência lexical, considerando a estrutura sintática, semântica e textual. No entanto, uma defasagem elevada desse tipo de conhecimento pode levar a dificuldades sérias de processamento do texto, pois este terá uma carga de informatividade mais alta do que o leitor é capaz de processar e integrar a seus conhecimentos anteriores.

Porém, a compreensão do texto é alicerçada não apenas pela interpretação adequada dos índices linguísticos, que contribuirão para a construção do processamento da referência (VAN DIJK; KINTSCH, 1983), mas também por índices baseados em conhecimentos capazes de recuperar relações entre conceitos, esquemas, o que é balizado por experiências vivenciadas pelo leitor, as quais comporão seu conhecimento enciclopédico, tema da próxima subseção.

\subsection{Conhecimento enciclopédico}

O conhecimento enciclopédico, ou conhecimento de mundo, encontra-se armazenado na memória de longo termo (KOCH, 2003). Conforme Koch e Elias (2010), refere-se a conhecimentos gerais sobre o mundo, bem como a conhecimentos alusivos a vivências pessoais em eventos espaço-temporalmente situados, permitindo a produção de sentido, “como se tivéssemos uma enciclopédia em nossa mente, construída de forma personalizada, com base em conhecimentos de que ouvimos falar ou que lemos, ou adquirimos em vivência e experiências variadas" (KOCH; ELIAS, 2010, p. 41). Por exemplo, ao reconhecer o substantivo "Peru" como um topônimo, o leitor recupera em sua memória informações relativas a esse país, localizando-o geograficamente (inclusive, não o confundindo com a ave homógrafa). E, ainda que o leitor nada saiba sobre o país e sua localização geográfica, o texto dá pistas de como esse elemento pode ser 
interpretado para sua coerência global, inclusive na relação com o texto não verbal.

Kleiman (2016) observa que esse tipo de conhecimento, acionado a partir de elementos formais no texto, pode ser adquirido tanto formal como informalmente. A autora afirma que o conhecimento que o leitor tem de determinado assunto permite-lhe fazer as inferências necessárias para relacionar diferentes partes do texto num todo coerente. Trata-se de um tipo de conhecimento relevante para a intepretação da macroestrutura do texto. Os conhecimentos linguísticos são imprescindíveis para que esse conhecimento seja acessado, pois eles permitem a interpretação da microestrutura do texto, sem o processamento da qual não se chega à macroestrutura. No entanto, esta só será adequadamente interpretada se o leitor puder fazer relações entre conceitos e ideias-chave do texto.

Como no caso do conhecimento linguístico, tomamos aqui alguns exemplos que ilustram a relevância do conhecimento de mundo para que ocorra a compreensão da proposta de redação. O texto pressupõe muitos conhecimentos partilhados, o que fica bastante evidenciado no texto-base (mais do que no restante da proposta), que aborda a temática da redação. Para que esse texto-base seja minimamente compreendido, o estudante precisa acionar vários conhecimentos armazenados na memória, que apenas exemplificamos a seguir, apontando para algumas áreas:

- História: conhecimento da história de Chico Mendes e sua luta, junto a outros seringueiros no norte do Brasil, pela criação de reservas extrativistas, conhecimento imprescindível para relacionar essa questão com o desenvolvimento sustentável da região Amazônica.

Geografia: localização espacial dos pontos citados, recuperando, por exemplo, o conhecimento de que o Acre fica no Brasil; de que a floresta amazônica localiza-se também no Acre, mas que se estende por outros estados e para além das fronteiras do Brasil; de que a expressão “do Atlântico ao Peru” traça uma linha da extensão da floresta Amazônica (na direção leste-oeste); da localização, no território brasileiro, dos estados da Amazônia (e o sul desta), de Mato Grosso e 
São Paulo; da localização do Brasil e da Argentina no mapa da América Latina; do que é o paredão dos Andes e de sua localização com relação à floresta e aos outros pontos geográficos citados; dos pontos cardeais (sul, norte) e da localização ocidental no mapa.

Geopolítica: conhecimento sobre a relação de território e posses de recursos naturais (floresta amazônica) e aspectos de ecologia e da importância das safras para o desenvolvimento econômico do país, que também impulsiona e acelera o desmatamento; compreensão sobre a noção de floresta nativa; sobre a geração de energia hidrelétrica como fonte mais comum de energia na América do Sul; sobre o estatuto da cana-de-açúcar e da soja na agroindústria brasileira; e sobre o papel dos estados do Mato Grosso e São Paulo na produção agrícola do país.

- Política: conhecimentos sobre direitos humanos; sobre o papel do estado na contenção do desmatamento, atuando, por exemplo, como fiscalizador e multador; e sobre a relação do estado com recursos financeiros internacionais.

Tecnociência: conhecimentos capazes de sustentar a compreensão de tecnologias, desde o processo mais básico de geração de energia hidrelétrica, o que vai apontar para a importância da água, até processos mais complexos, como o sensoriamento remoto, considerando, por exemplo, suas possibilidades com relação ao desmatamento.

Além disso, para entender a proposta, faz-se necessário recuperar conhecimento sobre fatos extratextuais, a partir de inferências feitas com base no conteúdo posto, como, por exemplo, o fato de existir desmatamento autorizado e não autorizado. Num nível mais elevado da interpretação semântica global, requer-se o acionamento de conhecimentos que leve à distinção de argumentos, fatos e opiniões como conceitos diversos, mas que se relacionam para a construção da coerência global do texto-base e deste em relação à proposta como um todo.

A partir do que é linguisticamente dado, é necessário trazer para a interação esses e outros conhecimentos correlacionados (que não daríamos conta, aqui, de elencar), os quais, em maior ou menor grau, são imprescindíveis para a 
compreensão do que são os "rios voadores" e para levar a inferências que deem conta da compreensão da macroestrutura semântica do texto, como a relação da reserva extrativista com o desmatamento, a relação do desmatamento com a chuva e a relação da chuva com o desenvolvimento econômico do país, por exemplo. Se essa interpretação da macroestrutura do texto-base não for acionada - o que exige, a todo momento, ativação de conhecimento enciclopédico -, também não será possível o processamento mais geral da proposta de redação, pois o estudante não terá condições de chegar a uma compreensão da validade das propostas citadas, muito menos de levantar hipóteses sobre suas possibilidades e limitações, conforme demanda a prova.

Embora a relação entre conteúdos conhecidos e novos seja dinâmica, e novos conceitos vão sendo formados com relação a conhecimentos anteriores, se uma parcela grande desses conhecimentos enciclopédicos não puder ser recuperada pelo leitor, o estabelecimento da coerência global do texto-base não será possível. Em outros termos, é necessário movimentar conhecimentos suficientes para ancorar as novas informações, de maneira a ampliar ou transformar qualitativamente o conhecimento. O estudante somente será capaz de entender um modelo de situação mental pessoal e específico de um texto sobre a importância dos rios voadores para a agricultura se tiver e aplicar um conhecimento mais geral sobre ciclo hidrológico e agricultura, por exemplo.

A falta de compreensão da temática a ser debatida não impede que o estudante entenda a prova como uma proposta de redação. No entanto, tal limitação impossibilita a resposta com o ato de fala que lhe é solicitado. Nesse sentido, o conhecimento enciclopédico assume relevância crucial na complexa dinâmica sociocognitiva envolvida no processamento textual. 


\subsection{Conhecimento sociointeracional}

Conforme Koch (2003), o conhecimento sociointeracional diz respeito ao conhecimento sobre as ações verbais, sobre as formas de interação pela linguagem. Na perspectiva de Van Dijk (2016a), esse conhecimento está ligado ao modelo episódico ou de situação, demandando do leitor a recuperação da representação cognitiva de acontecimentos, ações, pessoas, e da situação sobre a qual o texto se baseia, conforme pontuado anteriormente.

Para realizar com êxito uma interação, além das estratégias de ordem cognitiva, que têm a função de permitir ou facilitar o processamento textual, quer em termos de produção, quer em termos de compreensão, também assumem papel relevante as estratégias interacionais e textuais, conforme aponta Koch (2003). Segundo a autora, estratégias interacionais visam a fazer com que os jogos de linguagem transcorram sem problemas, evitando o fracasso da interação, enquanto as estratégias textuais (que não deixam de ser interacionais e cognitivas, em sentido lato) dizem respeito às escolhas textuais que os interlocutores realizam com base em seus objetivos interacionais.

Trata-se da ativação de "modelos cognitivos que o produtor possui sobre práticas interacionais diversas, histórica e culturalmente constituídas" (KOCH; ELIAS, 2010, p. 44). Engloba os conhecimentos do tipo ilocucional, comunicacional, metacomunicativo e superestrutural, os quais são acionados de maneira dinâmica e interdependente.

O conhecimento ilocucional nos permite reconhecer os objetivos ou propósitos pretendidos pelo produtor do texto, em uma dada situação interacional (KOCH, 2003). Trata-se de conhecimentos sobre os tipos de ato de fala, que podem ser verbalizados por meio de enunciações características ou por vias indiretas, o que exige dos interlocutores o conhecimento necessário para a captação do objetivo ilocucional. A proposta de redação e o contexto em que é mobilizada requerem que o estudante se localize como parte da interação proposta e reconheça, primeiramente, que se trata de uma injunção/instrução, e, 
a partir disso, identifique o efeito perlocutório esperado (produção de um determinado tipo de texto).

Nesse processo, exigem-se conhecimentos suficientes para reconhecer o tom injuntivo do texto como integrante desse ato de fala, considerando a função do modo imperativo no direcionamento de ações, por exemplo, bem como para reconhecer a organização geral do texto como parte dessa proposta, o que passa pela compreensão da função do texto-base e do texto não verbal, que participam da construção dos objetivos ilocucionais.

$\mathrm{O}$ conhecimento comunicacional refere-se às normas gerais da comunicação humana (KOCH, 2003). Para processar o texto, o estudante precisa acionar conhecimentos relativos a outros contextos de comunicação de qual tomou parte, para que consiga reconhecer o texto não apenas como um ato de fala, conforme seus conhecimentos ilocucionais, mas também como uma interação suficiente e adequada a tal ato. Aqui, as experiências escolares anteriores são imprescindíveis para interpretar a função comunicacional do texto. No entanto, não são suficientes se tais experiências não o prepararam, de alguma maneira, para essa situação exofórica específica, com objetivos diversos daqueles postos em situações de produção de texto na escola, conforme citamos anteriormente. Em outros termos, a representação do discurso na memória dependerá dos pressupostos do estudante sobre os propósitos e outras motivações subjacentes do locutor (Inep), assim como seus próprios objetivos e motivações ao aceitar a interação proposta.

O conhecimento metacomunicativo, conforme Koch (2003), é aquele que permite ao locutor assegurar a compreensão do texto e conseguir a aceitação pelo parceiro dos objetivos com que é produzido e diz respeito a vários tipos de ação linguística, como a introdução de sinais de articulação ou apoios textuais, atividades específicas de formulação ou construção textual. No caso da leitura da proposta, o estudante precisa reconhecer os tipos de ações linguísticas dadas, com destaque à porção final do texto, onde está a orientação propriamente dita, bem como interpretar adequadamente a função dos apoios textuais (verbais e não 
verbais) como elementos que buscam assegurar a compreensão do texto e embasar a ação dele esperada.

O conhecimento superestrutural diz respeito aos esquemas textuais $(\mathrm{KOCH}, 2003)$. Esse tipo de conhecimento permite reconhecer textos como exemplares adequado aos diversos eventos da vida social; envolve, também, conhecimentos sobre as macrocategorias ou unidades globais que distinguem os vários tipos de textos, sobre a sua ordenação ou sequenciação, bem como sobre a conexão entre objetivos e estruturas textuais globais. São esses conhecimentos que fazem com que o estudante não estranhe, por exemplo, o fato de um textobase estar inserido na proposta de redação.

Van Dijk e Kintsch (1983) explicam que estratégias de compreensão usadas para formar macroestruturas dependem da presença de certos sinais no texto, que indicam ao leitor os elementos do texto que devem ser considerados macrorrelevantes. No caso em análise, o estudante precisa reconhecer a proposta de redação com tal, compreender o que é texto-base e o que é enunciado da questão, compreender as várias partes do texto (título, texto-base, texto não verbal, orientação para a produção, atenção a aspectos que direcionam o modo como a interação deve ser feita). Nesse processo, ativam-se modelos de práticas comunicativas próprias da esfera escolar, levando em conta o modo de organização e aspectos como conteúdo, estilo, função e suporte de veiculação.

Ademais, a proposta requer o processamento estratégico da informação não verbal. Van Dijk (2016a) observa que, embora isso raramente conduza, por si só e de forma independente, às representações semânticas, geralmente facilita as estratégias de compreensão do texto. Ou seja, aqui se recuperam esquemas ou formas convencionais que caracterizam um tipo específico de texto, ativando conhecimentos suficientes para atribuir funções específicas às sequências textuais que compõem o texto (VAN DIJK, 2016a).

De acordo com Van Dijk (2016b), o conhecimento socialmente compartilhado é o que suporta as inferências que o leitor é capaz de fazer com base na coerência local e global do texto. Segundo o autor, tal conhecimento geral pode constituir a base cognitiva de gêneros e estruturas de discurso que 
expressam tal conhecimento diretamente. Observamos que a proposta está carregada de elementos que demandam a recuperação de estruturas de conhecimento genérico subjacentes, envolvendo relações contextuais e parâmetros fundamentais da realidade.

Ainda que as características prototípicas do gênero proposta de redação possam guiar a interpretação, a compreensão do texto só se realiza de forma satisfatória se for considerado o contexto mais geral, conforme observa Van Dijk (2016a, 2016b). Embora haja algumas características definidas para o gênero, como o título "Proposta de redação", a presença de texto de apoio, o enunciado com orientações para a produção, com predominância do modo imperativo etc., podemos dizer, em consonância com Dijk (2016a), que esse gênero é assim definido especialmente em termos de seus traços contextuais: o entorno, os participantes (e seus papéis, suas identidades e relações), o tipo de atividade (teste) e suas bases cognitivas (objetivos, conhecimentos, crenças, ideologias etc.).

Conforme analisa Kleiman (2016), quanto mais conhecimento textual o leitor tiver, quanto maior a sua exposição a todo tipo de texto, mais fácil será sua compreensão, pois "o conhecimento de estruturas textuais e de tipos de discurso determinará, em grande medida, suas expectativas com relação aos textos, expectativas estas que exercem um papel considerável na compreensão" (KLEIMAN, 2016, p. 23). Esse conhecimento vai garantir a ativação do frame relacionado a exames e, de forma mais ampla, à produção de texto, que envolve diferentes etapas, como a leitura, a versão rascunho e a versão final.

\section{Conclusão}

Buscando responder à pergunta de pesquisa que motivou este estudo, "Que conhecimentos são demandados na leitura dessa proposta de produção textual?”, apontamos, com base na perspectiva sociocognitivista-interacionista, alguns dos conhecimentos requeridos na interação em questão. Muitos aspectos não foram citados por não caberem em uma abordagem que se pretende ilustrativa. No 
entanto, o que levantamos serve para reforçar o que já é de conhecimento geral quando se faz uma abordagem científica da leitura: esta configura-se como um processo altamente complexo, que envolve a atuação conjunta de uma complexa rede de fatores de ordem situacional, cognitiva, sociocultural e interacional (KOCH, 2010).

Todos os sistemas de conhecimento aqui abordados vão sendo construídos ao longo das experiências interacionais e de práticas sociais (VAN DIJK, 2016a). Eles são subjetivos na medida em que dependem das vivências peculiares ao meio sociocultural em que vivem os interactantes, uma vez que as situações são compreendidas como parte de situações ou contextos sociais mais complexos, o que implica o uso e a construção de informações a respeito das relações entre os acontecimentos e as situações em que eles ocorrem.

Nesse contexto, a escola assume função relevante como lugar de se explorarem, de forma planejada, estratégias diversas, que precisam ser aprendidas e reaprendidas, até serem automatizadas e darem sustentação ao desenvolvimento de novas estratégias, que vão gradativamente se complexificando conforme o estudante vai avançando em sua escolaridade.

Ao chegar ao final do Ensino Médio, espera-se que o estudante tenha desenvolvido uma série de estratégias procedurais e que consiga fazer uma combinação de informações de diversas fontes. Na prova do Enem, o estudante já precisa ter construído uma rede de conhecimentos que vai ancorar a compreensão do texto; caso contrário, o processamento textual se dará de forma deficitária com relação aos objetivos postos para a interação.

Nesse sentido, para além de explicitar a complexa atividade que é a leitura, a perspectiva sociocognitiva-interacionista sobre o processamento do texto reforça o argumento de que um trabalho com a língua pautado apenas nos aspectos linguísticos propriamente ditos é insuficiente e ineficiente, quer para a leitura, quer para a produção de texto. O processamento do texto implica a articulação coordenada de uma série de estratégias cognitivas, linguísticas e não linguísticas, uma vez que, diante de um acontecimento, o leitor precisa ativar um ou mais dos três tipos de informação que a interação requer: sobre o próprio 
acontecimento, sobre a situação ou contexto e sobre pressuposições cognitivas (VAN DIJK, 2016a). Nessa dinâmica, a compreensão do texto não se dá como uma construção passiva, mas como um processo interacional no qual o leitor interpreta as ações do locutor (VAN DIJK, 2016a), as localiza e localiza a si mesmo em determinado contexto social.

Essa complexidade fica ainda mais acentuada se considerarmos que a leitura é apenas parte da produção de texto demandada. A escrita vai requerer ainda outros conhecimentos e outras habilidades linguísticas. No entanto, embora a leitura da proposta não dê conta do ato perlocutório esperado do estudante, ela é imprescindível para viabilizar a atividade de produção textual. Uma leitura deficitária compromete todo o processo de produção, o que sinaliza a importância de se enfatizarem conteúdos relacionados à habilidade de leitura nas aulas de língua portuguesa. 


\section{Referências}

BORTONI-RICARDO, Stella Maris. O professor pesquisador: introdução à pesquisa qualitativa. São Paulo: Parábola, 2008.

BRASIL. Ministério da Educação. Instituto Nacional de Estudos e Pesquisas Educacionais Anísio Teixeira. Exame Nacional do Ensino Médio: Enem 2008. Brasília: MEC, 2008. (Prova 1 - Amarela). Disponível em: http://download.inep.gov.br/educacao_basica/enem/provas/2008/2008_ama rela.pdf. Acesso em: 03 mar. 2010.

CORBARI, Alcione Tereza. Elementos modalizadores como estratégia de negociação em textos opinativos produzidos por alunos de Ensino Médio. 2013. Tese (Doutorado em Letras e Linguística) - Programa de Pós-Graduação em Letras e Linguística, Universidade Federal da Bahia, Salvador, 2013.

DUCROT, Oswald. Argumentação e "Topoi” Argumentativos. In: GUIMARÃES, Eduardo (org.). História e sentido na linguagem. Campinas, São Paulo: Pontes, 1989. p. 13-38.

DUCROT, Oswald. O dizer e o dito. Tradução de Eduardo Guimarães. Campinas: Pontes, 1987.

KLEIMAN, Angela. Texto e leitor: aspectos cognitivos da leitura. 16. ed. Campinas: Pontes, 2016.

KOCH, Ingedore Grunfeld Villaça. O texto e a construção dos sentidos. 9. ed. São Paulo: Contexto, 2010.

KOCH, Ingedore Grunfeld Villaça. Desvendando os segredos do texto. 2. ed. São Paulo: Cortez, 2003.

KOCH, Ingedore Villaça; ELIAS, Vanda Maria. Ler e escrever: estratégias de produção textual. 2. ed. São Paulo: Contexto, 2010.

KOCH, Ingedore Villaça; ELIAS, Vanda Maria. Ler e compreender: os sentidos do texto. 2. ed. São Paulo: Contexto, 2006.

MOREIRA, Herivelto; CALEFFE, Luiz Gonzaga. Metodologia da pesquisa para o professor pesquisador. 2. ed. Rio de Janeiro: Lamparina, 2008.

VAN DIJK, Teun A. Cognição, discurso e interação. Apres. e org. de Ingedore Villaça Koch. 7. ed. 1. reimpr. São Paulo: Contexto, 2016. 
VAN DIJK, Teun A. Discurso-cognição-sociedade: estado atual e perspectivas da abordagem sociocognitiva do discurso. Letrônica, Porto Alegre, v. 9, n. esp. (supl.). s8-s28, nov. 2016b.

VAN DIJK, Teun A. Semantic Macro-Structures and Knowledge Frames in Discourse Comprehension. In: JUST, Marcel Adam; CARPENTER, Patricia A. Carpenter (ed.). Cognitive Processes in Comprehension. Hillsdale: Lawrence Erlbaum Associates, 1977. p. 3-32.

VAN DIJK, Teun A.; KINTSCH, Walter. Strategies of Discourse Comprehension. New York: Academic Press, 1983.

Artigo recebido em 15 de maio de 2020 e aceito em 6 de julho de 2020. 